\title{
APPLICATION OF ABRASIVE SAND BLASTING PROCESS IN MICRO GEOMETRICAL CUTTING EDGE OPTIMIZATION
}

\author{
Tofana Vasile Gabriel, Stefan Sattel, Marcel Sabin Popa
}

Preliminary notes

This paper aims to establish the parameters of optimization and geometrical improvements for the micro-geometry of solid carbide drills through the application of sand blasting process. The effects of sand blasting over the cutting edge and also upon the micro geometry of the tool body are to be taken into consideration. This process is one of the most common ones used in the solid carbide tool fabrication, being implemented in various ways, not always achieving the best results. The micro geometrical optimization of the cutting edge is concentrated on two important parameters, edge radius and $K$-factor alignment, both of these having a critical role in the tool life and over the cutting parameters. The improvement of this optimization process can also be achieved by combining it with other known processes aiming at the same result.

Keywords: cutting edge optimization; micro geometrical optimization; sand blasting; solid carbide drill

Primjena abrazivnog postupka pjeskarenja u mikro geometrijskoj optimizaciji oštrice

Prethodno priopćenje Cilj je ovoga članka odrediti parametre optimizacije i geometrijskih poboljšanja u mikro geometriji svrdla od tvrdog karbida primjenom postupka pjeskarenja. Treba uzeti u obzir učinke pjeskarenja na oštricu i na mikro geometriju tijela alata. Taj postupak je jedan od najuobičajenijih postupaka u izradi alata od tvrdog karbida koji se primjenjuje na različite načine, ne uvijek s najboljim rezultatima. Mikro geometrijska optimizacija oštrice usmjerena je na dva važna parametra, polumjer oštrice i $K$-faktora centriranja, koji su od odlučujuće važnosti za vijek trajanja alata i parametre rezanja. Ovaj se postupak optimizacije može poboljšati i kombiniranjem s drugim poznatim postupcima čiji je cilj postizanje istog rezultata.

Ključne riječi: optimizacija oštrice; mikro geometrijska optimizacija; pjeskarenje; svrdlo od tvrdog karbida

\section{Introduction}

This paper aims to establish quality optimization and geometrical improvements for the micro-geometry of solid carbide (SC) drills when drilling 42CrMo4 Material. The cutting edge improvement through rounded edge geometries has been intensely studied in the past decades, Fig. $1[1]$.

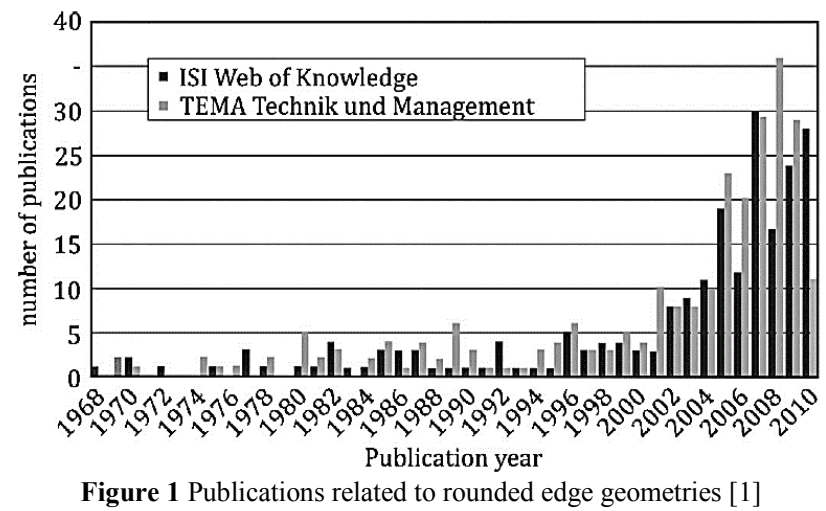

Based on the success drill performance in cutting applications has to date largely been based on significant advances in reproducible and accurate tool production processes, modifications of drill point geometry, and optimization of the rake angle distributions along the drill lips and the chisel edge. The preparation of cutting edge radii was mainly done by manual processes at that early beginning and is still a production state in many companies, although the brushing and sand blasting applications have developed quite a lot in the past years. The development of new more accurate measurement has led to an increase in the application of prepared cutting edges [1].
In every cutting process the cutting edge suffers under the thermal and mechanical impact provided by the chip formation process, therefore the optimization of the chip flow over the cutting edge and into the flute. The more defined the cutting edge is the less damaging the effects of cutting are, and also the quality of the machined surface is drastically affected by the cutting edge geometry. The demands of modern production are high productivity and high process reliability. One place these demands can be met is in cutting edge preparation [1].
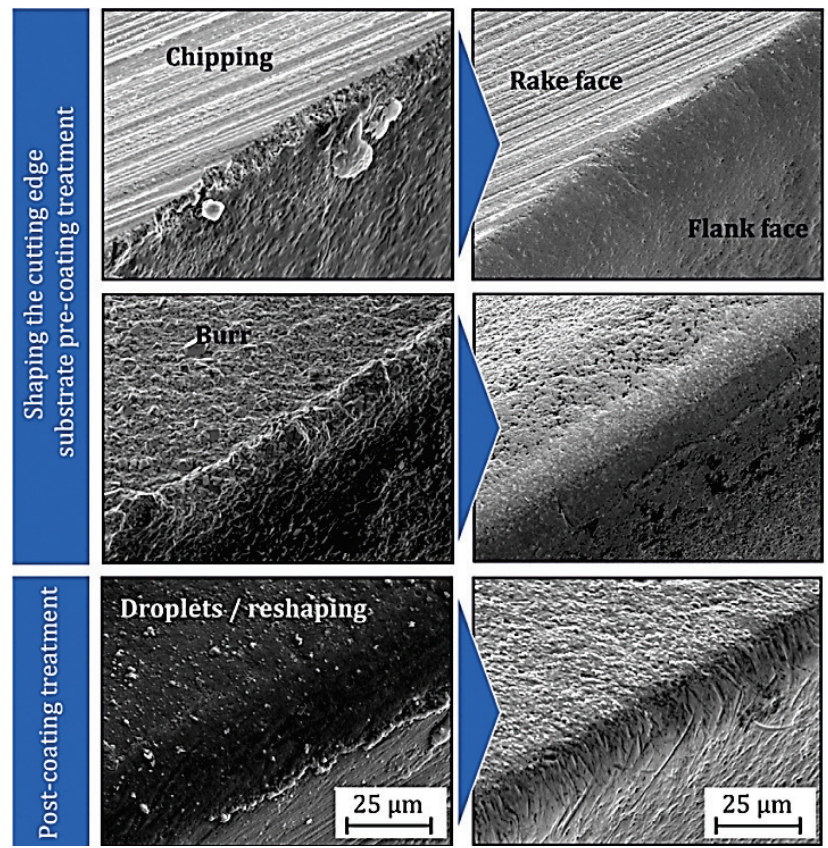

Figure 2 Main effects of the cutting edge preparation [1]

In Fig. 2 the main effects of a cutting edge preparation are summarized. In addition to the reduction 
of the chipping after grinding and burrs after sintering the preparation can be used as a post-coating treatment. Before the coating process, cutting edge preparation influences the surface topography and the residual stresses in the substrate. Regardless of the cutting procedure, the advantages of cutting edge preparation are scientifically proven by many investigations $[1,2,3]$.

The conclusion of many researched papers showed that a good cutting edge optimization lead to a more secure process and therefore to a better cutting performance, all this thanks to an enhanced cutting edge stability [1]. This stability is given by the geometrically defined cutting edge on which the cutting forces are equally distributed. But the positive effects of cutting edge optimization does not end here, there has been reported a rise in adhesion strength of the coating material on the tool surface, facilitated by the smoother surface of the cutting edge. The perfect cutting edge form and geometry are related to the machining process and workpiece material and the process conditions are also to be taken into consideration [1,4]. Fig. 3 shows the impact that the two most used cutting edge optimization processes have on the drill tip, this being the brushing and sand-blasting processes. This is why our current study focuses on the wet sand-blasting procedure due to the more rounded and smooth edge.
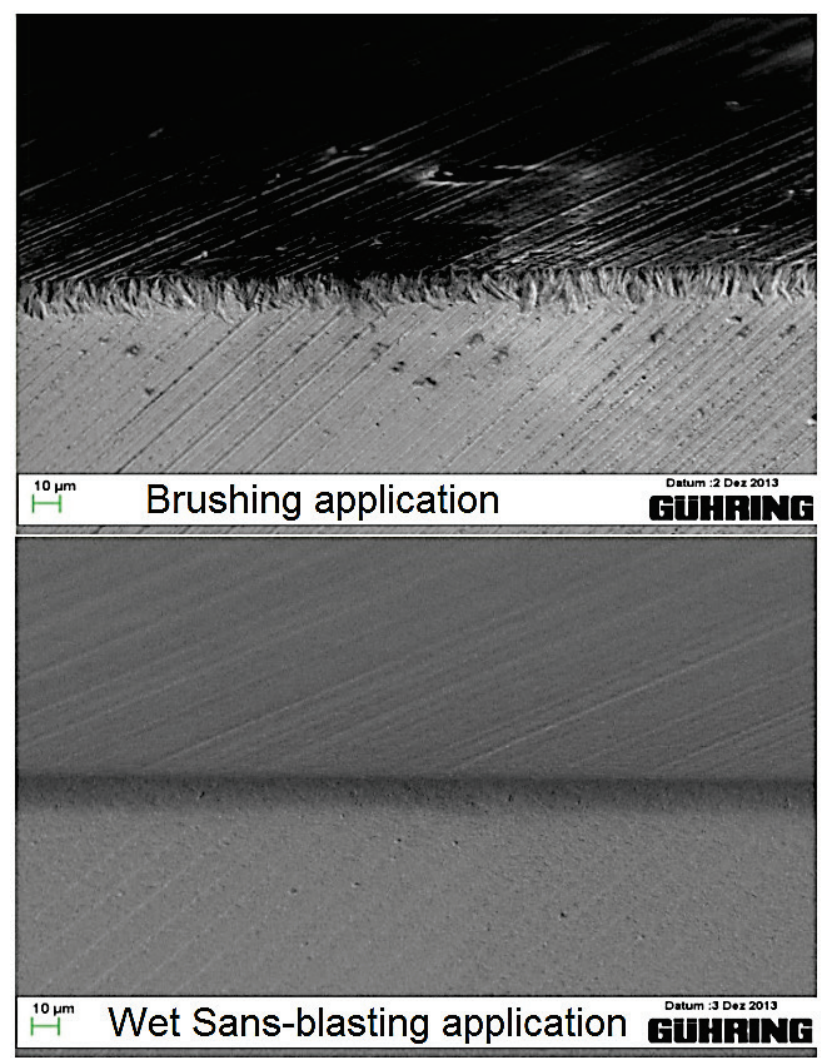

Figure 3 Cutting edge after brushing and sand blasting

Flank wear is one of the most important aspects that affect tool life and product quality in machining. However, only few works were published to identify the mechanism behind flank wear mainly due to the complexity in metal cutting process. At the present time, the most dominant flank wear mechanism is believed to be the abrasion by the hard inclusions in a work material, which results in the scoring marks. Sharp cutting edges are usually considered detrimental to cutting processes because of their low stability and low impact resistance [5]. Conversely, Yen et al. [6] postulate that round edges reduce the initiation of notch wear, since they have higher impact resistance. Thus, the earliest studies on cutting edge design are focused on the edge geometry, specifically on the edge radius.
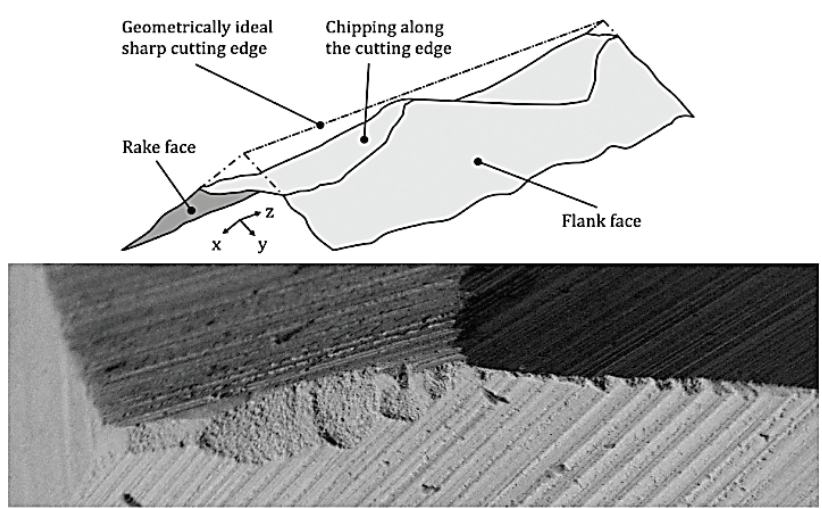

Figure 4 Cutting edge chipping after grinding [1]

Cutting edge geometry is characterized by microgeometry and edge topography. The edge topography describes the surface structure of the cutting edge. It is highly impacted by microscopic damage like burrs or chipping [1]. The most common verification process for describing the cutting edge geometry without having to use an electron microscope is to determine the roughness of the surface. The bigger the roughness is the bigger the chipping effect and deviation from the geometrically ideal edge is. The schematic illustration of a chipped cutting edge after the grinding process is depicted in Fig. 4 [1].

In order to define a geometrical shape of the cutting edge the different types of shape definitions have to be studied. In essence there are only two kinds of geometrical shapes that can be achieved without much effort, with cost efficient processes. The first shape is characterized by a chamfer between the flank surface and rake surface, having the option to add one or more chamfers with different angle to the final cutting geometry, Fig. 5 [1].

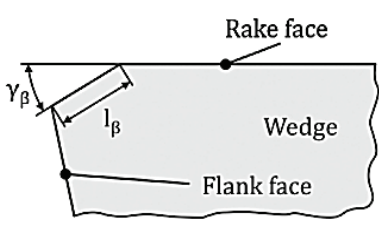

Single chamfer

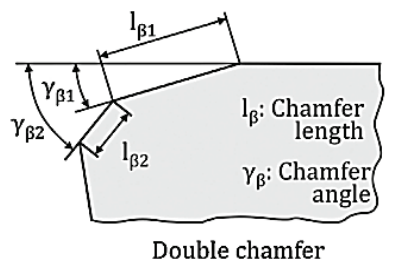

Double chamfer
Figure 5 Parameters for cutting edge chamfer characterization [1]

Here the chamfer is the result of $\gamma_{\beta}$, chamfer angle for each chamfer segment, and $\iota_{\beta}$, chamfer length for each segment. Furthermore the chamfer is also categorized by the $K$-Factor, which describes the orientation of the chamfer onto the rake ore flank side. Studies have shown that the ideal case is given when the orientation of the new edge is right in the middle $K=1$, so the cutting forces are equally distributed and there is an even wear.

The second geometrical shape for the cutting edge is a round shape, a radius, which is a more complex shape which requires more parameters to be characterized [1]. 
To determine the cutting edge a constant circle is to be fitted into the intersection of the flank face and rake face, so several points need to be defined on the intersection by means of a measurement system. At least three of these measured points need to be determined in order to fit a circle on to the cutting edge, with the radius $r_{\beta}$.

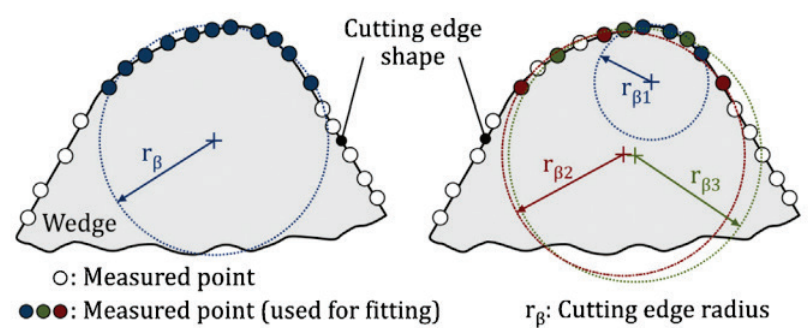

Figure 6 Inaccuracy when describing cutting edge geometry with one single radius [7]

In order to have an accurate result, it is advised to measure as many three-point combinations as possible and the arithmetic sum of all the $r_{\beta}$ will be the final radius of the cutting edge, Fig. 6 [7]. Due to the fact that measuring so many three-point combinations is very complicated, Denkena et al. [8] established another method, the form-factor method, also known as the $K$ Factor method.

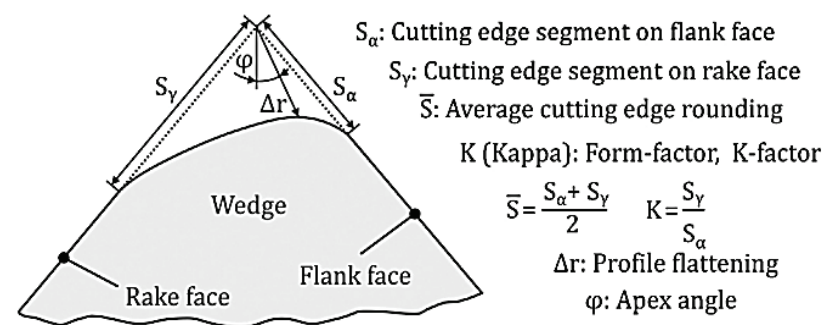

Figure 7 Form-factor methods for cutting edge characterization [8].

In Fig. 7 the form-factor method is described, $S_{\alpha}$ and $S_{\gamma}$ are the cutting edge segments introduced to measure the distance between the separation point of the cutting edge rounding and the tool tip of an ideal sharp cutting edge at flank face and rake face, respectively. Based on these values, the average cutting edge rounding $\bar{S}$ specifies the dimension and the form-factor $K$ (Kappa) specifies the orientation of the rounding at the cutting edge. In addition, profile flattening $\Delta_{r}$ and apex angle $\varphi$ are used to characterize the tools bluntness by measuring the shortest distance and the shift between ideal sharp tool tip and actual shape of rounding [8].

\section{Experimental setup}

At the current moment in the tool manufacturing industry there are many different optimization processes in use, each of them focusing on the cutting edge, but from another perspective. For the process to be truly efficient it needs to be both secure and reproducible and perhaps most important with the lowest economic impact. Having studies many different types of optimization processes, the one with the most advantages would be the wet sandblasting process. The wet sandblasting process is from the first point of view the most undefined, due to the excessive spreading of blasting mix, but after a more careful look the blasting jet can be very precise when combining the right parameters:

- Orientation

- Blasting speed

- Fluidity

- Focusing

- Pressure

- Nozzle diameter

- Blasting method (combination of rotation speed and modulation speed).

The first two parameters that need to be correlated to one another are nozzle diameter and blasting pressure, so depending on the nozzle diameter the blasting pressure needs to be adjusted in order to obtain a linear smooth blasting jet, for our experiment a round nozzle type was used.

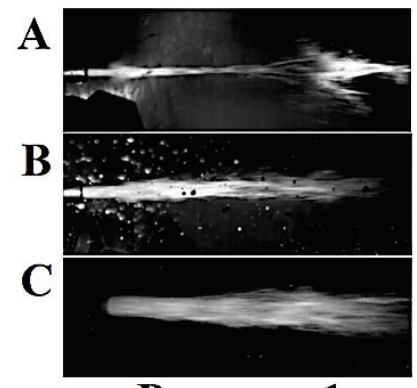

Pressure 1

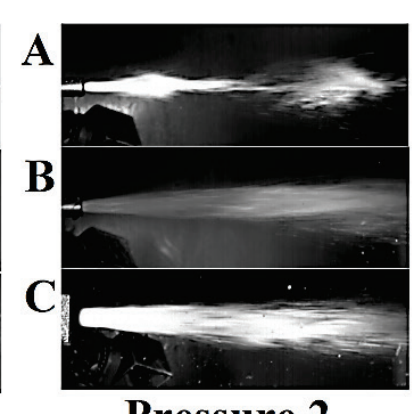

Pressure 2
Figure 8 Nozzle - blasting mix pressure combination

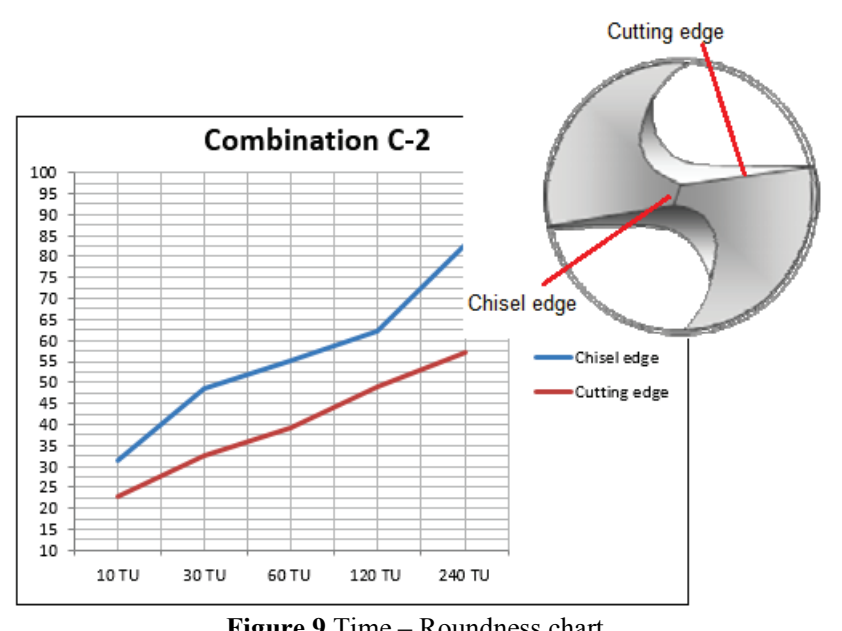

As mentioned before, the blasting parameters need to be correlated between each other. Fig. 8 shows the different nozzle and pressure combinations, for example the combination between nozzle A and pressure 1 is very misfortunate, the jet is very erratic, having a very discontinuous pattern. This type of combination is to be avoided, as due to the discontinuous jet the abrasive effect would be drastically influenced. The best results were obtained with the combination $\mathrm{C}-1$ and $\mathrm{C}-2$ where the dismantling effect over the solid carbide cutting edge is the most linear and focused. The other 3 combinations of nozzle type and pressure obtained less satisfying results, so their use was not recommended. Here we can trace the process in time units. Each unit results in certain edge roundness, so in this way the cutting edge radius is easily predicted and measured. 
Fig. 9 exemplifies exactly the predictability of the sand blasting process once all the parameters are established and known. But in order for this chart to be accurate all the parameters need to be constant. This is why any change in the tool body material or different sand /water combination will have a very big influence on the optimization process itself.
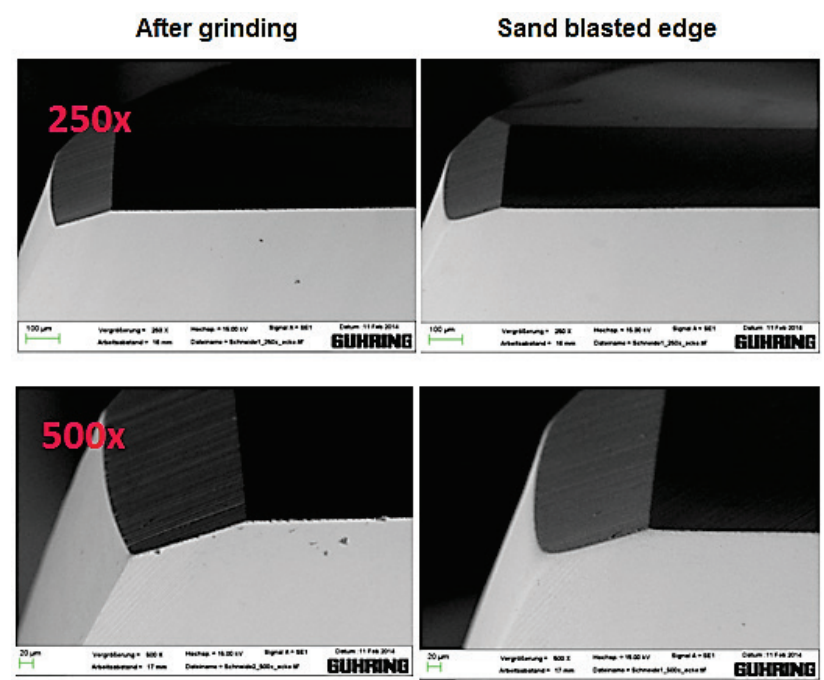

Figure 10 Sand blasting effects on cutting edge

The wet sand blasting process returns many benefits with a minimum input of time, labour and material. In Fig. 10 the cutting edge has suffered a few micro geometrical improvements, first of them being the new edge geometry, with a defined profile. Having now a more solid appearance the cutting edge is more durable and predictable in the cutting process. The cutting corner is more flattened, this way the wear will appear later and the material exclusion from the tool body will drastically be minimized. The third benefit given by this process is that the more adhesive surface with the coating can better build contact. The biggest problems with tool wear are due to coating peeling, giving access of the machined material to the raw solid carbide, which can often build a chemical reaction between them, concluding to a various types of wear. In this case the cutting edge and corner have a smooth transition to the neighbouring surfaces, allowing the coating material to have a solid foundation. The last but not least of the benefits of this process are to be seen when the tool has grinding errors, for example when the cutting edge is chipped. In this case the wet sand blasting rounds the sharp edges without influencing the initial edge geometry, as seen in Fig. 11.

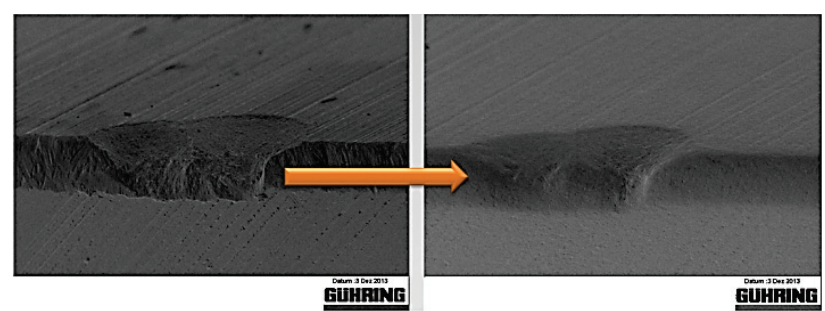

Figure 11 Cutting edge error improvements through wet sand blasting

\section{Testing and conclusions}

The testing part of the paper was made after implementing all the parameters of the wet sandblasting process into the production process. In the following tables the cutting edge radius has been measured by optical microscopy. In order to find the best cutting edge radius for the testing drill, with a diameter or $6,8 \mathrm{~mm}$, there have been optimized three lots of drills, manufactured from solid carbide DK460UF, aiming a small, medium and large radius, meaning 1,5\%,2\% and $3 \%$ from the drill diameter. The $K$-Factor was also of high importance, being measured for all the three lots, having a very big impact over the tool life and wear mechanism. The optimal $K$-Factor is considered to be $K=1$, meaning the orientation of the cutting edge is neutral. Another important feature being followed was the process stability for more than one drill (Fig. 12).

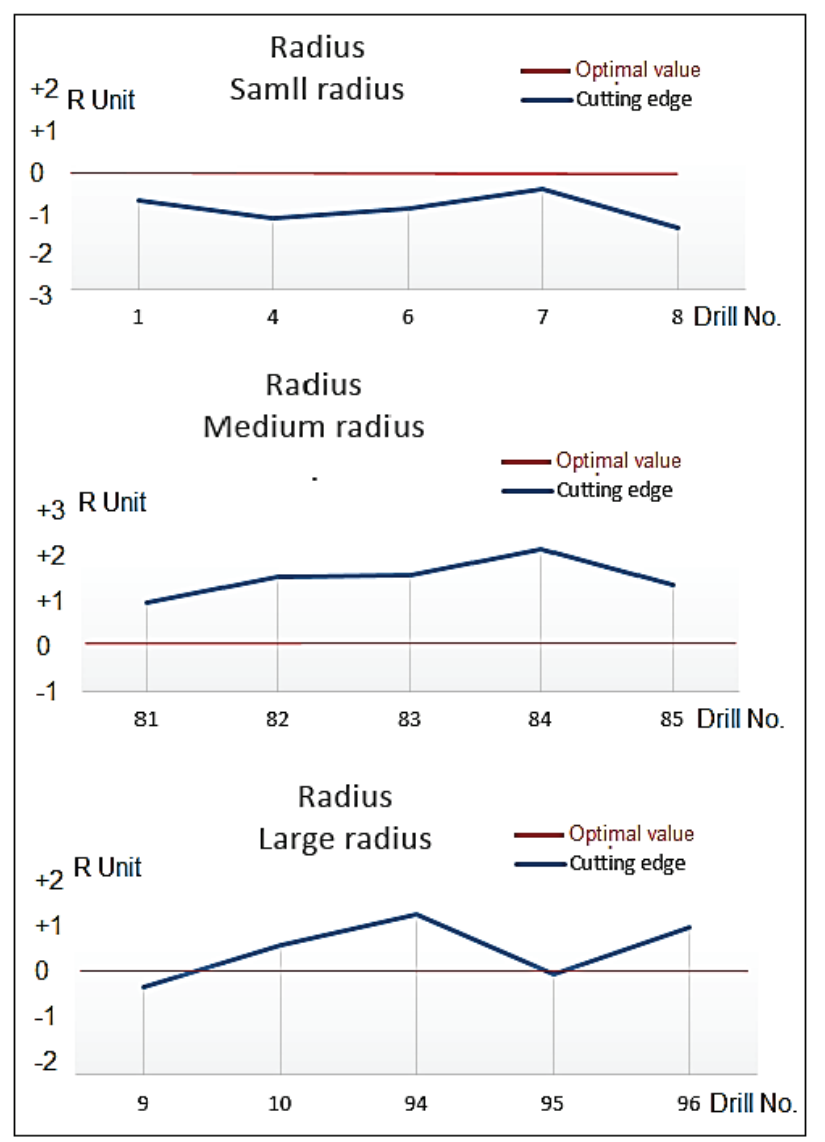

Figure 12 Radius values

The optimal value for the different types of radius and $K$-factor has been established by other tests conducted previous to this, which focused on finding the best radius and $K$-factor for different diameters and drill tip geometry.

After putting all the drills through the optimization process, and measuring the resulting values, the tendency of the process can be seen. The radius of the cutting edge is very near to the optimal value, one $R$ unit represents 2 $\%$ of the optimal radius value, meaning that the process is very linear and highly stable, offering a high process safety. In Fig. 13 the $K$-factor resemblance the same process stability, having a very linear character.

The slightly higher value than the optimal one for the drills with a medium radius and a large radius is due to the drill movement during the blasting process. The drill movement represents the number of rotations that a drill must take during the blasting process, for example a large 
radius requires more rotations in order for the blasting jet to grind the equal amount on each cutting edge.

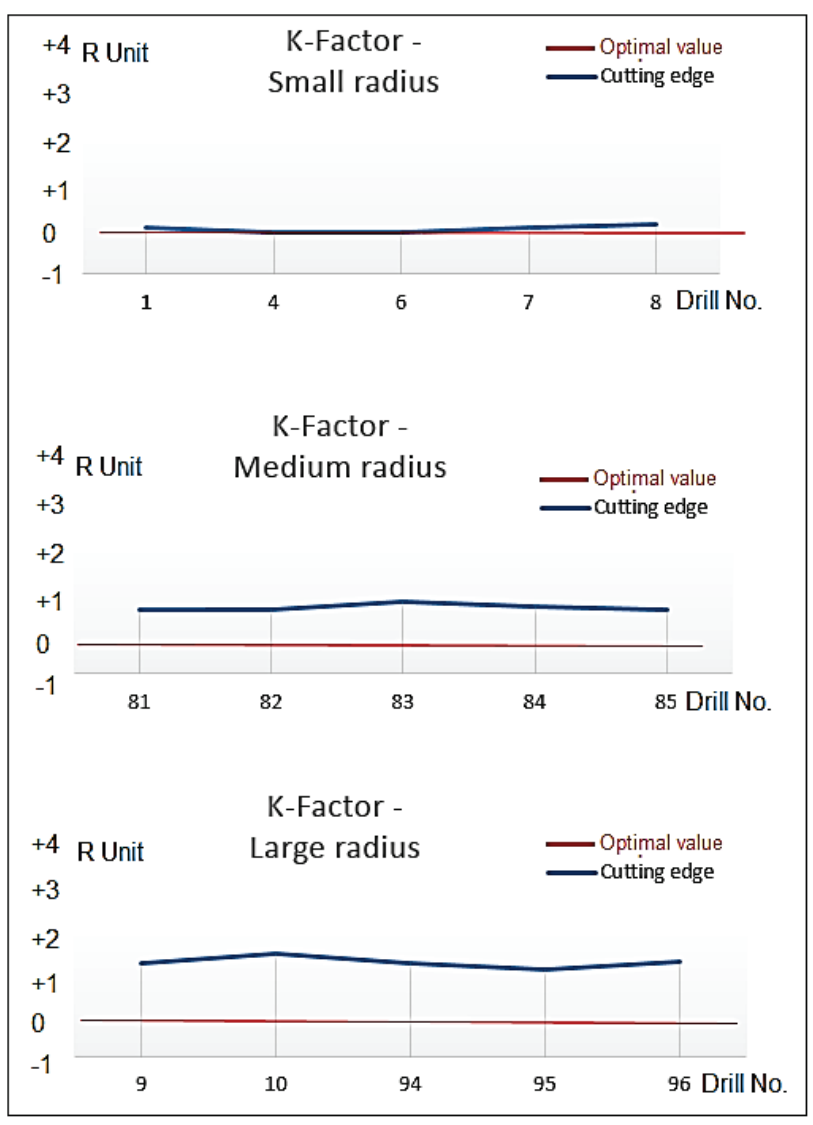

Figure $13 K$-factor values

After developing a secure manufacturing process and adjusting the whole parameters the drills were put to the test in comparison with a reference drill from the production. The work piece material was manufacturing steel $42 \mathrm{CrMo} 4$. It can be seen that the tool lifetime of a drill with an optimized cutting edge is more than doubled while using identical machining parameters and conditions.

The values in Fig. 14 were obtained by subjecting each of the 12 drills to a cutting process in which alloy steel 42CrMo4 was machined with standard cutting parameters Tab. 1.

Table 1Standard cutting parameters

\begin{tabular}{|l|c|c|}
\hline \multicolumn{1}{|c|}{ Parameter } & Unit & Value \\
\hline Cutting speed $\left(v_{\mathrm{c}}\right)$ & $\mathrm{m} / \mathrm{min}$ & 110 \\
\hline Feed $(f)$ & $\mathrm{mm} / \mathrm{rot}$ & 0,2 \\
\hline RPM & $\mathrm{rot} / \mathrm{min}$ & 5149 \\
\hline Feed speed $\left(v_{f}\right)$ & $\mathrm{mm} / \mathrm{min}$ & 1030 \\
\hline Cutting depth $\left(a_{\mathrm{p}}\right)$ & $\mathrm{mm}$ & 34 \\
\hline $\begin{array}{l}\text { Cooling system } \\
\text { (internal / external / MQL) }\end{array}$ & - & Internal coolant \\
\hline Pressure / Volume & bar $/ 1 / \mathrm{min}$ & $35 / \sim 81 / \mathrm{min}$ \\
\hline
\end{tabular}

This provided exact information on the state of the edge throughout the entire testing process, the values were compared to each other and then introduced in the graphic from Fig. 14. Taking into consideration that the tool life from the best optimized drill is $100 \%$, the best result from all of the tested drills, the standard drills lasted less than a third. The standard drills are taken out of the normal production process, from the factory line, having edge roundness between $5 \div 7 \%$ which is induced through automated brushing processes. The optimized drills reach three times as much tool life without showing the tendency to develop crack at the edge surface. The final conclusion which can be drawn is that by combining the necessary parameters for wet sand-blasting and in the right order, the result is an optimized micro geometrical cutting edge which shows a higher and more stable tool life and secures cutting processes.

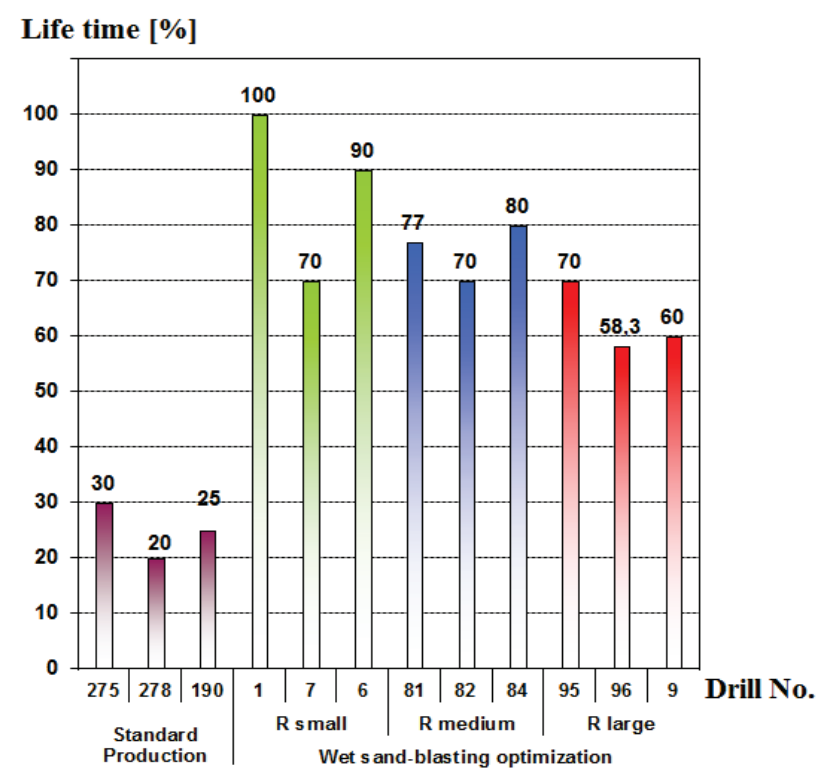

Figure 14 Tool life and cutting edge wear

\section{Acknowledgments}

This paper was supported by the R\&D Centre at the Gühring KG Tool Company, Albstadt, Germany.

\section{References}

[1] Denkena, B.; Biermann, D. Manufacturing Technology 63: Cutting edge geometries. // CIRP Annals. 63, (2014), pp. 631-653. DOI: 10.1016/j.cirp.2014.05.009

[2] Bouzakis, K-D.; Michailidis, N.; Skordaris, G.; Bouzakis, E.; Biermann, D.; M'Saoubi, R. Cutting with Coated Tools: Coating Technologies, Characterization Methods and Performance Optimization. // CIRP Annals. 61, (2012), pp. 703-723. DOI: 10.1016/j.cirp.2012.05.006

[3] Denkena, B.; Breidenstein, B. Cohesive Damage of PVDcoated Cutting Tools - A Result of the Residual Stress Distribution. $/ / 9^{\text {th }}$ Int. Conf. "THE A Coatings", Thessaloniki, Greece, 3-5 October 2011, pp. 89-97,

[4] Bassett, E.; Köhler, J.; Denkena, B. On the Honed Cutting Edge and its Side Effects during Orthogonal Turning Operations of AISI1045 with Coated WC-Co Inserts. // CIRP Journal of Manufacturing Science and Technology. 5, (2012), pp. 108-126. DOI: 10.1016/j.cirpj.2012.03.004

[5] Karpat, Y.; Özel, T. Mechanics of high speed cutting with curvilinear edge tools. // International Journal of Machine Tools and Manufacture. 48, (2008), pp. 195-208. DOI: 10.1016/j.jimachtools.2007.08.015

[6] Yen, Y-C.; Jain, A.; Altan, T. A finite element analysis of orthogonal machining using different tool edge geometries. // Journal of Materials Processing Technology.146, (2004), pp. 72-81. DOI: 10.1016/S0924-0136(03)00846-X 
[7] Wyen, C-F. Rounded Cutting Edges and Their Influence in Machining Titanium, (PhD-Thesis) ETH Zürich, Zürich, 2011.

[8] Denkena, B.; Reichstein, M.; Brodehl, J.; de León-García, L. Surface Preparation, Coating and Wear Performance of Geometrically Defined Cutting Edges. $/ / 8^{\text {th }}$ CIRP Int. Workshop on Modeling of Machining Operations, May 10 11, Chemnitz, 2005.

\section{Authors' addresses}

Tofana Vasile Gabriel, PhD Stud. Eng.

Technical University of Cluj Napoca-Romania,

Manufacturing Engineering Dept.,

Blvd. Muncii, No. 103-105, 400641, Cluj Napoca, Romania

S. C. Gühring S. R. L.

Cluj Napoca, Romania

E-mail: gabriel.tofana@guehring.de

\section{Stefan Sattel, PhD Rer-Nat}

Gühring KG, Head of Research and Development Department, Winterlingen Street, No. 12,

72488, Sigmaringen-Laiz, Germany

E-mail: stefan.sattel@guehring.de

Marcel Sabin Popa, Prof. PhD Eng.

Technical University of Cluj Napoca-Romania,

Manufacturing Engineering Dept.,

Blvd. Muncii, No. 103-105, 400641, Cluj Napoca, Romania

E-mail: mpopa@mail.utcluj.ro 